Proceedings

\title{
Exogenous AGEs, Microbiota and Their Role in Chronic Diseases
}

\author{
Jaime Uribarri * \\ Icahn School of Medicine at Mount Sinai, New York, NY 10029, USA \\ * Correspondence: jaime.uribarri@mountsinai.org
}

Published: 30 October 2020

\begin{abstract}
This is a short presentation that explores several areas: 1) definition of Advanced Glycation End products (AGEs) in general and their pathogenic mechanisms of action; 2) definition of exogenous (mostly dietary) AGEs and their effects in vitro and in vivo in several experimental models in mice; 3) exploring the potential role of dietary AGEs in human health and disease by looking at clinical trials involving patients with diabetes mellitus and other chronic conditions; 4) development of the "AGE hypothesis" as an important pathogenic risk factor for chronic nontransmissible human diseases; 5) Overall review of different sources of AGEs in the body; 5) review evidence that AGEs may form within the gastrointestinal lumen under some conditions and therefore contribute to the body AGE pool; 6) review of the potential interactions between exogenous AGEs and the microbiota; 7) detailed description of our current understanding of the metabolism of exogenous AGEs ; and finally 8) listing potential future directions for research in the field.
\end{abstract}

Publisher's Note: MDPI stays neutral with regard to jurisdictional claims in published maps and institutional affiliations.

(C) 2020 by the authors. Submitted for possible open access publication under the terms and conditions of the Creative Commons Attribution (CC BY) license (http://creativecommons.org/licenses/by/4.0/). 